\title{
Research on reflective teaching mode based on Teacher Professional Development
}

\author{
Liping ZHANG, Pijuan GONG, Hongjun LIU \\ Weifang Vocational College, Wei Fang, 261041, China.
}

Keywords: Teachers' professional development, reflective teaching, reflective teachers.

\begin{abstract}
With the development of the times, reflective teaching has become the teacher professional development is one of the most important ways. Try to explore a more scientific, reflective teaching model of dynamic, for teachers in the reflection of teaching practice in the field can provide the theory reference, for rational reflection on their teaching practice, so as to continuously improve the professional level, as soon as possible from the experienced teacher change for reflective teachers in order to adapt to the requirements of modern society to the teachers' professional growth. Using the method of literature study, comparative study of law and, around the reflection to the construction of teaching mode, explores the theoretical basis of this model, goal, content, process, methods and Evaluation, and to explore the growth of reflective teacher. Describes the use of reflective teaching on Teachers' professional growth of significance, further analysis of the model structure and internal operation process and method, and analyzes the reflection of teaching mode implementation strategies and conditions.
\end{abstract}

\section{Introduction}

Since the 80 s of the 20th century, all the countries in the world are in reforming the traditional teacher learning and growth mode and seek new teacher professional growth way, is under such a historical background, the reflective teaching began to rise and development, and with its unique advantages by the respected education. Reflection teaching in essence difference to experiential teaching, it maximizes the pursuit of rationalization and optimization of teaching practice, from simply asked for the improvement of teaching practice, not only to promote the progress of teachers' education concept and solution of practical problems in teaching, and promote their professional growth, but also conducive to improving the quality and level of education. Based on this, This paper tries to explore a more scientific, dynamic reflective teaching mode, in order to facilitate the teachers on their teaching practice rational reflection, as soon as possible to achieve change from the experienced teacher to reflective teacher, and continuously improve their professional level, to adapt to modern society of teacher professional growth requirements.

\section{The significance of reflective teaching to teachers' professional development}

Basic understanding of teacher professional development.

The connotation of teacher professional development.

The connotation of teacher professional development, the current understanding of many scholars, the author believes that the professional growth of teachers is the professional quality of teachers to upgrade, evolution and rich process.

At first, the teacher is unlimited potential, sustainable development of the individual. Burke in the United States believes that the basic hypothesis of the concept of "teacher professional development" is: teachers need continuous development. Teacher is an ordinary person, is a development of the individual, any teacher in mind and unlimited development potential and space. Secondly, the teachers should also be regarded as a "professional", but this kind of understanding is not the teacher's actual state. However only such a position, to arouse teachers' potential, enhance the level of education of the. Third, teachers should become learners, researchers and cooperation. Blackman (Blackman That teacher is always continuous learners, this kind of study is "professional growth. 
Teachers should also be active researchers. At the same time, in the world of life of teachers and students teaching benefits teachers as well as students, students grow in the development of teachers, teachers in the growth of the students development.

Ways of teachers' professional development.

The positioning of the current teacher professional quality is: Teacher's work is a form of professional, but is not a mature professional. This positioning is we construct the basis of reflective teaching model of teacher professional development process. At present, our teachers' professional growth activities refers to the new teacher's vocational training and on-the-job teacher's training and education, this mode of training tend to emphasize the technology of knowledge is in the practice of teaching pedagogy, psychology knowledge, principle and technical proficiency.

It should be pointed out is that in our country the existing educational resources are scarce and regional distribution is not balanced conditions, which can be regarded as a teachers' professional development effective way, but the problem is that essentially said that this kind of training pattern ignores it in primary and secondary school teachers, so it is difficult to guarantee the level of teachers' professional development. From a practical point of view, it in a certain extent, promoted the promotion of teacher's teaching skills and teaching strategies of optimization, but did not promote teachers' professional growth quality leap. Specific performance theory of indoctrination is in the majority, content, form and teaching practice out of joint. The current some teachers in primary and middle schools in-service training mainly For teachers of some short-term training of educational theories, make small and medium-sized school teachers get the new educational concepts and knowledge, and helped to change their teaching ideas, optimize the teaching strategy, improve teaching skills. But the training of teaching practice guidance for success.

At home and abroad in foreign countries, the teacher professional development mode is a famous American scholar of the valley of reflective teaching mode construction point of view, the valley summarizes five kinds of reflection mode. In practice, teachers should be in the five kinds of reflection model is established between the organic connection, the realization of organic complementary. The problem is, the valley of the five kinds of reflection mode in Teachers' professional development, to do each other's organic connection, just a good idea, in the concrete practice of the lack of effective guidance or lack of operation. Through the analysis, the author thinks that reflective teaching is teachers' professional growth of the effective one of the ways, and to expand the reflective teaching can't Don't build a kind of operable reflective teaching mode, and promote teacher professional development.

\section{Reflective teaching}

To prepare students as Schon in the United States that dominate the American professional education is "technical teaching thoughts and education practice too much emphasis on the pure theory of indoctrination, despise the practice problem solving, ignoring the students to solve the problem of comprehensive ability training. In this sense, the normal colleges and universities a wide range of subject curriculum and pedagogy, psychology and teaching method of the course can be up to do in the future a teacher knowledge and thought. As a result, the traditional teacher education is based on a" first theory and practice "idea to design. This kind of" theory first, practice "idea is the current teacher training mode of thought foundation. So the cultivation of "technical proficiency" has become the essential goal of teacher education. Schoen's critical point of view, no doubt laid the theoretical foundation for reflective teaching.

The author thinks, ponder over the meaning of teaching actually represents the is superior to the traditional way to teacher's professional growth progress. Therefore, it should be so to understand reflective teaching: it is to optimize the education idea to solve practical problems in teaching for the purpose, to a more reasonable teaching practice to better for the power of the teacher all-round development process of growing up.

The significance of reflective teaching to teachers' professional development

The professional growth of teachers objectively requires teachers individuals and groups with strong professional development consciousness, only teachers on their professional growth be a conscious state to become a conscious action, and timely adjust their teaching behaviors and activities, 
in order to realize the ideal professional development. Specifically, reflection of teaching for teachers' professional growth significance mainly the following points.

One, reflective teaching is conducive to the promotion of teachers' teaching practice ability.

Professional beliefs are at the highest level in Teachers' professional quality, which directly influence and restrict the other aspects of teachers' professional quality structure. Through the following cases, it shows how reflective teaching can promote teachers' professional development.

Apologize to the students

When the bell rang, I found sitting against the wall position of classmates are still whispering to each other, I immediately criticized them. In the next classroom learning, I just found that I criticize the female students have been with tears. In order not to affect the classroom teaching, I did not go to intervene until after class, I put her name to my office to ask reason. At first, she hung his head, silent, in my repeated questioning, she to say. In fact, the bell rang her deskmate is gossip, she is to remind him, can happen to be I saw, I do not indiscriminate gave her a meal of criticism, so she felt very wronged. I just know I am wronged her, hastened to apologize to her. However, after a few days she had always had the shadow had his smiling face.

Say "seeing", I see it with my own eyes, or blamed the students, which is the profound lesson. The child's heart is a tender and fragile, hurt is not easy to heal. As our teachers, whenever the criticism of the students before, be sure to ask yourself things clear yet? Fact is that right? I criticized justified?? do not by subjective imagination is hasty.

This case tells us that classroom teaching is not a closed system, but an open system, it has a rich and complex characteristics. Case the last of a series of questions, changing the views on the nature of the classroom teaching the teachers, caused the change of his view of classroom teaching. In education and teaching, similar such teaching cases too numerous to mention, as long as teachers are good at observation, thinking and reflection and to observe and ponder and reflect upon the results into practical education behavior, their educational beliefs will be constantly revised and improved, the more advantageous to the education teaching work.

Teachers should through the teaching of reflective thinking on their own teaching behavior, teaching according to the behavior and teaching results are to examine and analyze, optimize and improve the bad behavior, methods and strategies, the teaching practice is more reasonable, so as to enhance the ability of teaching practice. Currently in the implementation of the new curriculum, teachers must pay attention to reflective teaching, improve their ability of reflection, and strive to achieve the change from the experienced teacher to reflective teacher.

\section{Reflective teaching is conducive to promoting the improvement of teachers' teaching theories.}

Directly in the awareness and understanding of the form the core of the theory teaching literacy is composed of teachers' professional quality. In the concrete teaching practice, each teacher will some of the problems in teaching, and support the understanding and the understanding of the teaching theory mainly has two types. One is the explicit theory, teacher is easy to realize and easy to report came out, the more vulnerable to outside of the new information and change, but this kind of knowledge and not on teaching behavior have a direct influence; the other is the implicit theory and the knowledge of teaching behavior has an important influence, but is not easy to be teachers' consciousness, and not susceptible to new information and change, but more To express oneself in the natural difference between also influenced by culture and habits. Of course, these two kinds of theoretical knowledge is not completely separate, explicit theory can be transformed into the implicit theory of teaching activities have a positive impact. Because the teacher awareness is not to own in the teaching practice of whether to adopt what theory, so it is not easy to find their own teaching behavior and explicit theory, in this case, the teacher's teaching behavior does not change. The teacher of teaching activities and students of careful observation and analysis, and through the teacher mutual observations and discussion, make explicit theory applied to the teaching in continuous In the process, the theory of implicit theory is enriched and developed.

Third, reflective teaching is conducive to promoting the improvement of teachers' educational 
research ability.

The new curriculum gives teachers with new meanings and requirements, the teacher should be a researcher, research in practice, reflection in study, grows in the reflection has gradually become research teacher. Reflective teaching emphasized by teachers become researchers, so that teachers have dignity and vitality, exhibit and other professionals such as lawyers, physicians considerable academic status, teachers from the role of the past, the characteristics of non professional "knowledge" to have professional academic level, so as to improve their social image and status.

Two, the exploration of reflective teaching model in the process of teacher professional development.

The structure of reflective teaching model.

In reflective teaching, teachers can through the reflection of their own experience in teaching, to advance the understanding of practical teaching, improve their teaching level and develop their professional ability. On the reflective teaching practice mode of operation, compared to the well-known have Aibai (J.W.Edlby) mode and Laabs Kay V.K.Laboskey, Aibai pointed out, the reflection of teaching reflection should plan, reflection of teaching, reflective evaluation three part constitute. Among them, the reflection plan is the starting point. Laabs Kay, reflective teaching by dynamic link (including internal and external), action links (including Scenarios, processes, attitudes, and content) and outcomes (including new understanding and solutions to practical problems).

The structure of reflective teaching mode should be composed of four steps or stages:

Motivation: includes two aspects: the internal motivation and external motivation. Intrinsic motivation of vocational teachers from individuals and groups of teachers' in teaching practice perception, which contains teacher's dissatisfaction with the teaching situation and improving the teaching practice, this is the reflection of teaching psychological factors, but also the fundamental factors. On the other hand, to adapt to the requirements of the development of teaching practice constitutes the reflective teaching of external motivation.

Planning stage: strengthening of individual and groups of teachers' reflection of motivation and the motivation in the appropriate conditions, promotes the teacher form reflection teaching plan brewing. In plan brewing process, teachers' personal and group based on research needs. Data were collected collation and analysis of data, and on the practice of teaching be constant reflection, make reasonable judgment of regularity and purpose, this judgment resulted in plans, and to create the necessary conditions, contemplate and plan how to perform.

Action stage: the reflective teaching plan execution phase. In action and actions related to the specific content of reflection, reflection, conditions and reflection is reflection of the specific steps, links, teaching reflection behavior of internal and external factors, the dynamic change process of teaching and need to pay attention to the matters, also involve the teacher individual and collective attitudes, emotions and values change is to teachers' teaching idea update, optimization, and to the student as a living "human" attitude and emotional changes, and teachers the professional ideal, value goal establishment and ability to achieve the cultivation and formation.

Evaluation stage: the evaluation of teaching reflective behavior, the standard is only two: first, the solution to the problem of real education, the two is the optimization of the teacher's own educational philosophy.

In order to get a more clear of reflective teaching mode, clear understanding and use, teachers in the teaching need to play a dual role: a role is a stage actor, another part is the audience or commentators. This dual role enable teachers to find things that exist in their subconscious, on their individual teaching behavior to obtain a kind of exposure to the outside, new understanding, new and better methods of promoting behavior change. Learn how to carry out reflective teaching.

The operation process of reflective teaching mode

Reflection on teaching process, the author thinks that the source for teachers' personal and group in teaching practice in the process of profound understanding, and to the teaching practice of strong dissatisfaction, the intrinsic motivation of vocational teachers strengthening, this is the reflection of the teaching of psychological factors, but also the fundamental factors. In addition, adapts to the requirements of the development of teaching practice constitute the reflective teaching of external 
motivation. The two motivated teachers to improve their teaching practice, promotes the teacher formation of reflective teaching plans and actions. In the run-up to the plan, teacher individual and collective due to have strong motivation for change in teaching practices, resulting in a Reflection on the practice of teaching and The ideas of teaching and teachers, and relates to the birth of practical step to promote reflective teaching plan formulation, in this process, the need to collect data, analyze data, and make a logical and objective judgment, the judgment that leads to the plan, and create the necessary conditions, contemplate and plan how to perform. In the stage of action, action, situation and process, also is the action of the specific steps and links and details, the teaching behavior of internal and external environmental conditions, teaching the dynamic change process and the need to pay attention to the matters related to the teachers' personal and collective attitude, emotion and values change, also is the update, optimization and the students For a living "human" attitude and emotional changes, as well as teachers vocational ideal, value goal establishment and ability to achieve the cultivation and formation. This is perhaps something in the process of teacher's professional growth to occur, is teachers' professional development goal and fundamental demand; evaluation of actions that should be considered, one is to solve the problems existing in the education, optimization of teachers educational concept. In the evaluation process, the teacher will encounter new specific experience found new problems, thus entered a new stage, to begin a new cycle.

\section{The implementation of reflective teaching mode.}

Reflective teaching has many practical forms and means. Teachers can adopt different methods according to their own teaching conditions. The author believes that the most effective way is to write teaching journals, listen to lectures and observe, and case studies.

First, the teaching of writing

Teaching log is the teacher's personal records. Therefore, it can be descriptive, can also be thinking. It is mainly record the teacher found in the process of teaching and research, the confusion, personal understanding, the interpretations and views.

The discussion stages of teachers in a class or after work, teaching log form of classroom teaching in the process of feeling and experience, as the reflection of the foundation. The teacher or alone to engage in introspection, or with their colleagues around you care about, analyze the causes, and puts forward solutions, and in the next teaching should pay attention to and take measures, this discussion is very easy to make teachers from his colleagues there to get a lot of inspiration and experience. The $\log$ so that teachers often reflect on teaching experience, teachers can also log as their own teaching case of a history of the development of the record to the feedback teaching success and shortcomings. Limp There are usually two types of feet: one is to write down the current account, one is the general summary of the experience.

By keeping a diary, teachers to rethink their teaching behavior and reflection becomes a habit, for action research to lay a good foundation. Therefore, every teacher should develop the habit of teaching journal writing, as a means of reflection, often summed up, often receive of their own teaching practice and comprehensive understanding. With the passage of time, will certainly be able to become a passionate about teaching and their own teaching characteristic and style of the excellent teachers.

Second, listen to lectures and observe

Interaction and communication is teachers to learn from each other, mutual promotion and common development an important way. The lecture is mainly to attend each other and colleagues to observe and analyze the teaching activities. Teachers can department as a unit, to attend each other, mutual learning, teachers to observe whether reasonable arrangements for the teaching process, such as: classroom management, teaching methods, students reflect, the relations between teachers and students, how to deal with problems in classroom teaching, to ensure the smooth progress of the activity teaching. Listening to enable teachers to each other and learn, brainstorming, learn from each other, common progress. This and the traditional listening class is fundamentally different, is not a teaching inspection, evaluation, but by listening to lectures This form, teachers observe the teaching, 
while taking note of the observed scene, found the problem, and then exchange views with each other objectively, and put forward the improvement measures to achieve the common improvement and common development purposes.

Classroom observation is a teacher of one of the important contents in the research on reflective teaching. According to situation of classroom observation, teacher of the existence of the problem analysis, research, design improvement scheme, and once again return to the classroom until the corresponding conclusion. Classroom observation can promote teachers' self reflection, adjust teaching ideas, improve the professional quality of teachers, improve the quality of teaching. Teachers should keep an open mind, emancipating the mind, actively participate in internal and external exchange activities, in order to develop.

Third, case study

Seek first to help demonstration with description of the case teaching in the teaching practice, it tells the story of teachers and students of the action, thinking, feeling. The case is not only telling a story, in particular case, it also contains the abstract theory and principles. A case study on the development and cultivation of Teachers of different viewpoints and theory of balance ability, help them from multi angle look at a problem. A case study so that teachers who are familiar with the concept, and then from the case of concepts and conclusions of the study, at the same time, the teachers and concepts and conclusions related problems, and with their direct teaching experience, on the previous stage And the proposed solution to ponder and discussion, and finally use the concepts and theories to demonstrate, to encourage teachers to seek the conclusion of the case may be.

\section{Conclusion}

Increase along with the time development, reflective teaching has become a teacher professional development is an important one of the ways. Reflective teaching is not only a promoting teachers' professional level, is to promote the self change of a kind of effective tool, it will not only to the teacher individual and group learning experiences have a profound impact and change of teachers' professional life attitude and values. Reflective teaching process is such a process, the teacher first explore the world change point of view and a new way to explain the new world, to further explore the attitudes and beliefs change and new meaning changes, and to explore their own teaching behavior changes. The change will have a profound impact on their professional perspective, the impact of their team concept and the specific teaching behavior.

Transition from experienced teachers reflective teachers is the requirements for teachers in the new era, to meet the requirements of the development, combining with the teaching practice construct a kind of operation of the reflective teaching model, reflection of the teachers will be included in the dynamic model, not only is effective and necessary.

\section{References}

[1] Wu Xiongchuan. Reflective teaching [M]. Shanghai: East China Normal University press.1999. [2] Rao Man, Yang Xiuyu, Deng Tao. Teacher professional development [M] Changchun: Northeast Normal University press,.2005:39-55.

[3] Yang Xiangyi,Li Jinqiao. Editor in chief, thinking, questioning and exploring -- the exploration of the cultivation of reflective teachers [M]. Fudan University press, 2006:51.

[4] Lv Hongbo. The method of teacher reflection [M]. Education Science Press.2006.

[5] Li Jinqiao. The basic way of teacher professional development to explore [J].Foreign elementary and secondary education.2005 (4).

[6] Zhong Xiuying, Weeks advanced. Teachers' Professional Development: reflective teaching from the perspective of [J]. China Education Journal, 2006 (11). 